\title{
Electroactive Thermoplastic Dielectric Elastomers as a New Generation Polymer Actuators
}

\author{
Chong Min Koo \\ Korea Institute of Science and Technology \\ $\mathcal{E}$ University of Science and Technology \\ South Korea
}

\section{Introduction}

Actuators or transducers, represent devices that directly convert electrical energy to mechanical energy and thus generate a force and motion. The fast growing industries of highly integrated electronics, medicals, and robotics, eagerly demand new types of transducers with flexibility, high energy efficiency and compactness, because conventional actuators including pneumatic actuators, motors, and hydraulic cylinders, have many restrictions such as heavy weight, rigidity, restrictive shape, complex transmission, and limited size. Electroactive dielectric elastomers have garnered much more attention as promising alternative candidates for next generation compact actuators or transducers than other electroactive materials such as electroactive ceramics, shape memory alloys, and even other electroactive polymers like conductive polymers and ionic polymer metal composites, owing to their attractive properties such as large electromechanical strain, fast response, high power to mass ratio, softness, facile proccessibility, and affordability (Pelrine et al. 2000a, 2000b; Shankar et al., 2007a, 2007b). For example, a comparison of the properties of electroactive dielectric elastomers and other widely used transducer materials lists in Table 1. Piezoelectric materials have quite fast and high energy efficient response, but produce a limited strain (Furukawa \& Seo, 1990). Shape memory alloys (Lagoudas, 2008), conducting polymers (Bay et al., 2004) and ionic polymer metal composites (Nemat-Nasser \& Wu, 2003) are capable of producing relatively large strain, but they suffer pretty slow response and poor coupling efficiency. In contrast, the electroactive dielectric elastomers have much superior actuation properties than others.

A dielectric elastomer film is compressed electrostrictively in the longitudinal direction, and spreads in the transverse planar direction, as an electric field is applied across dielectric film thickness throughout the electrodes, illustrated in Figure 1. A dielectric elastomer film is coated with compliant conductive electrodes such as carbon grease and silver grease. When the external electric field is removed, the film is recovered to original shape owing to its shape memory property. That is to say, the electric actuation of the dielectric elastomer is a reversible process. 


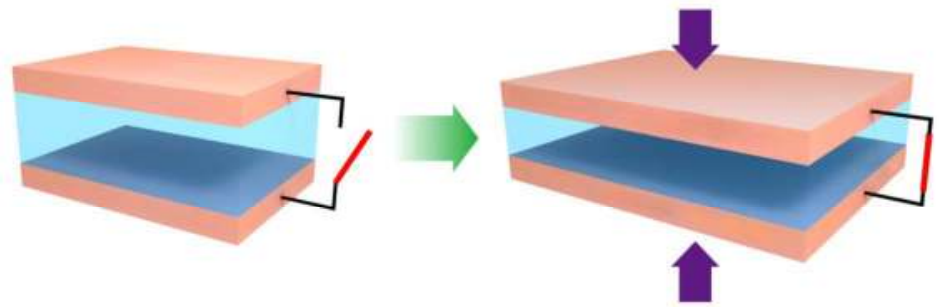

Fig. 1. Illustration of electric actuation of the dielectric elastomer actuators.

Unlike piezoelectricity, which has a linear relationship with applied electric field strength, this electric actuation of dielectric elastomers demonstrates that the total thickness strain, $\mathrm{s}_{\mathrm{z}}$ has a quadratic relationship with the applied electric field $\mathrm{E}$, as delineated by the following eq. (1) (Pelrine et al. 2000a, 2000b).

$$
s_{z}=R_{33} E^{2}
$$

where a thickness strain, $\mathrm{s}_{\mathrm{z}}$ represents a thickness change $\left(\mathrm{t}-\mathrm{t}_{0}\right)$ divided by initial thickness $\left(\mathrm{t}_{0}\right)$, and $R_{33}$ represents the sensitivity of the strain response of a material to the applied electric field.

\begin{tabular}{|c|c|c|c|c|c|c|}
\hline Type & $\begin{array}{l}\text { Maximum } \\
\text { strain (\%) }\end{array}$ & $\begin{array}{c}\text { Elastic } \\
\text { energy } \\
\text { density } \\
\left(\mathrm{Jcm}^{-3}\right) \\
\end{array}$ & $\begin{array}{l}\text { Coupling } \\
\text { efficiency } \\
\left(\mathrm{k}^{2}\right)\end{array}$ & $\begin{array}{l}\text { Specific } \\
\text { density } \\
\left(\mathrm{g} \mathrm{cm}^{-3}\right)\end{array}$ & $\begin{array}{c}\text { Response } \\
\text { speed }\end{array}$ & References \\
\hline \multicolumn{7}{|l|}{$\begin{array}{c}\text { Conventional dielectric } \\
\text { elastomer }\end{array}$} \\
\hline Acrylic with prestrain & 380 & 3.4 & 85 & 1 & Fast & {$[\mathrm{a}][\mathrm{b}]$} \\
\hline $\begin{array}{c}\text { Silicone with prestrain } \\
\text { Thermoplastic }\end{array}$ & 63 & 0.75 & 63 & 1 & Fast & [a] \\
\hline $\begin{array}{l}\text { dielectric elastomer } \\
\text { with prestrain }\end{array}$ & 250 & 0.15 & 85 & 1 & Fast & [d] \\
\hline Piezoelectric ceramic (PZT) & 0.2 & 0.1 & 52 & 7.7 & Fast & [a] \\
\hline Piezoelectric polymer (PVDF) & 0.1 & 0.0024 & 7 & 1.8 & Fast & [a] \\
\hline Shape memory alloy (TiNi) & $>5$ & $>100$ & 5 & 6.5 & Slow & [a] \\
\hline Conducting polymer (PANI) & 10 & 23 & $<1$ & 1 & Slow & {$[\mathrm{a}][\mathrm{c}]$} \\
\hline
\end{tabular}

[a] Referred from Pelrine et al., 2000b.

[b] Referred from Kornbluh et al., 2000.

[c] Referred from Kornbluh et al., 2002.

[d] Referred from Shankar et al., 2007.

Table 1. Comparison of actuator materials.

Thermoplastic dielectric elastomers, in this book, represent microphase-separated block copolymers such as a poly (styrene- $b$-ethylbutylene- $b$-styrene) (SEBS) or a poly (styrene- $b$ ethylbutylene- $b$-styrene)-graft-maleic anhydride (MA) triblock copolymers, described in Figure 2. For the first time, Shankar et al. (2007a, 2007b, 2007c) demonstrated that the SEBS 
thermoplastic dielectric elastomers with microphase-separated nanostructures had not only the very high electric actuation performance even at low electric field, but also versatile tunability of their properties, even though the SEBS exhibited pretty low dielectric feature. The thermoplastic dielectric elastomers differ from conventional homopolymer dielectric elastomers such as acrylics, silicones, fluoropolymers and natural or synthetic rubbers in several aspects such as nanostructure morphology, shape memory property and electric actuation mechanism(Drobny, 2007; Hamley, 2003; Kim, et al. 2011).

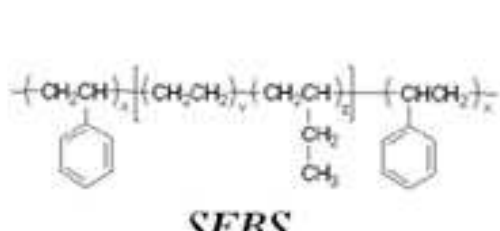

\section{SEBS}

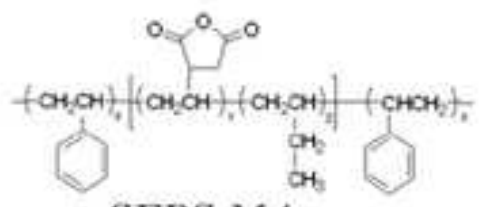

\section{SEBS-MA}
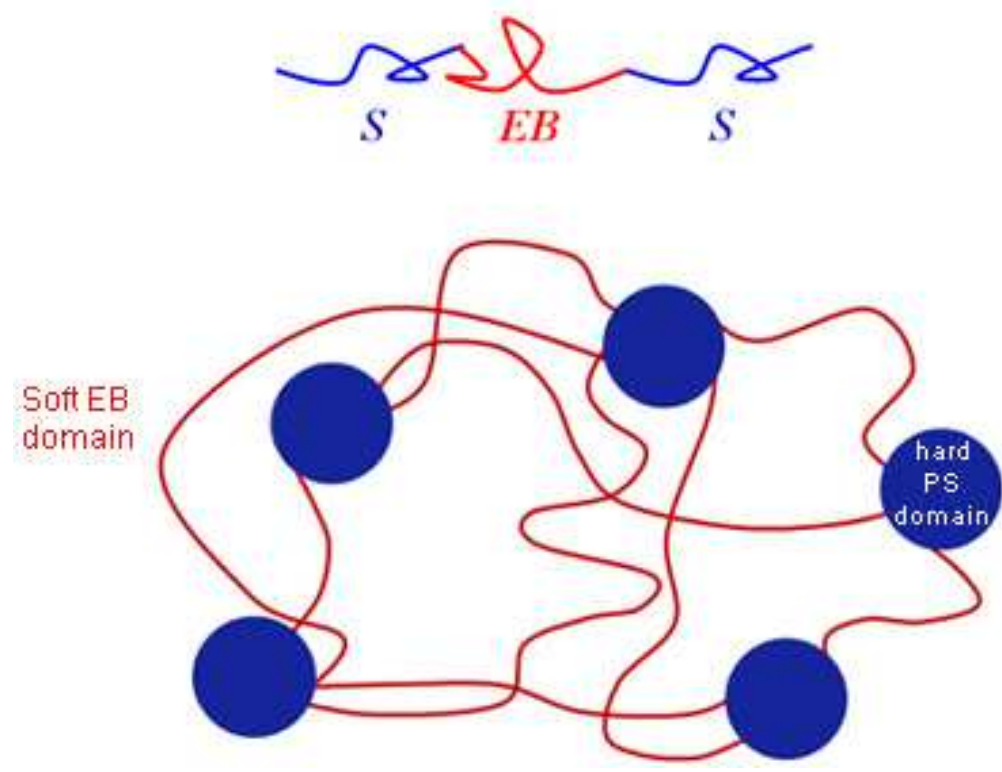

Fig. 2. Molecular and chain structures, and segregation morphology of the thermoplastic dielectric elastomers

Several well-organized reviews and books have already been published and summarized properties, mechanisms and applications of electroactive polymers including the conventional dielectric elastomers (Bar-Cohen, 2004; Brochu \& Pei, 2010; Carpi et al., 2008; Carpi \& Smela, 2009; Kim \& Tadokoro, 2007; O'Halloran et al., 2008; Pons, 2005; Shankar et al., 2007; Shahinpoor et al., 2007). However, electroactive thermoplastic dielectric elastomer, sometimes referred to as electroactive nanostructured polymers (ENP), is a quite new terminology in the field of electroactive polymers (Chmidt et al., 2008; Jang et al., 2011; Kim et al 2010, 2011; Shankar et al., 2007a, 2007b, 2007c, 2008; Vargantwar, 2011). Thus, this book 
will focus on demonstrating unique electric actuation properties of the thermoplastic dielectric elastomers.

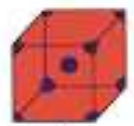

$\mathrm{S}$

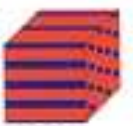

C

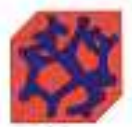

G

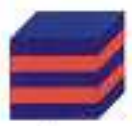

$\mathrm{L}$

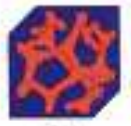

$\mathrm{G}^{\prime}$

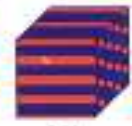

$\mathrm{C}^{\prime}$

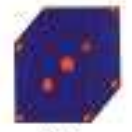

$\mathrm{S}^{\prime}$
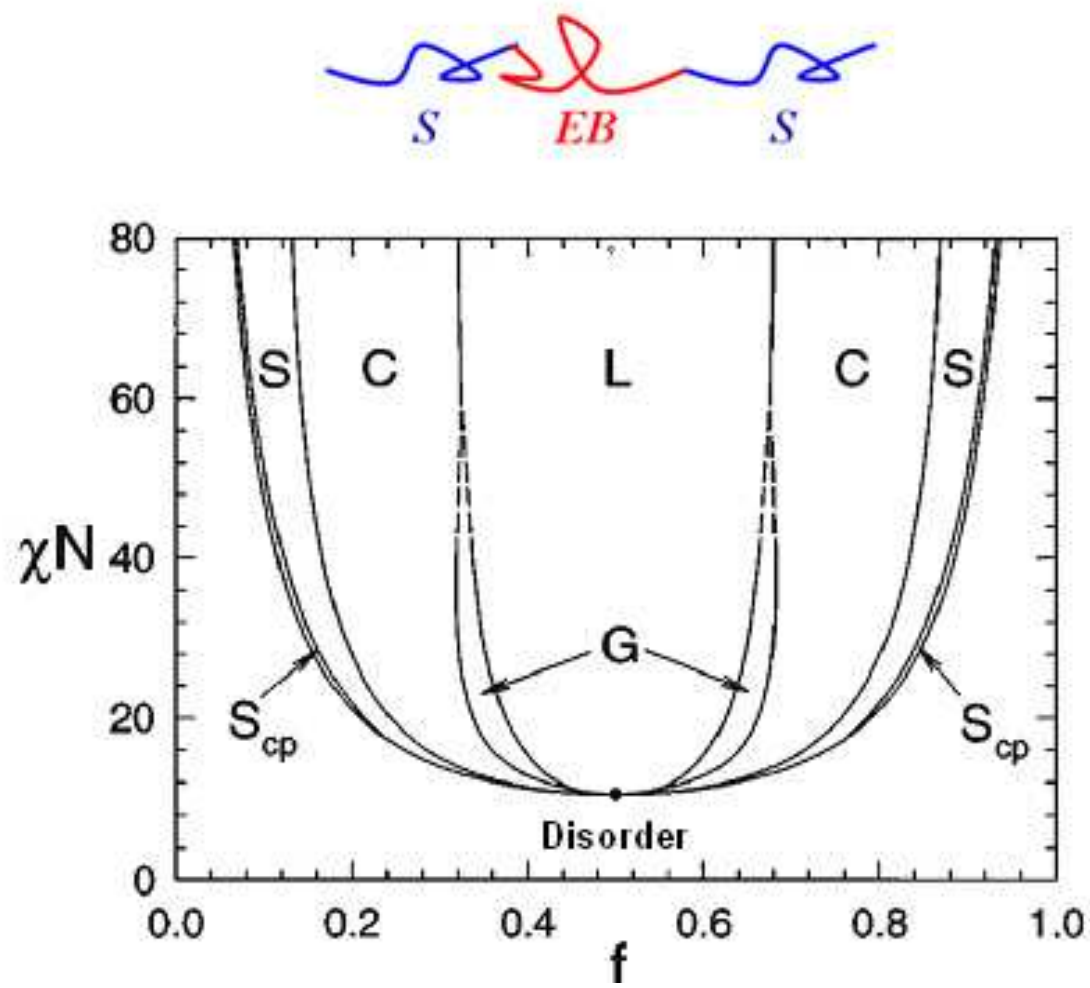

Fig. 3. Phase diagram of two component triblock copolymer. S, C, G and L represent sphere, cylinder, gyroid, lamellae nanostructures, and $\chi$ and $\mathrm{N}$ represent Flory-Huggins interaction parameter and molecular weight, respectively (Matsen \& Bates 1996).

\section{Nanostructures of thermoplastic dielectric elastomers}

Thermoplastic dielectric elastomers like a poly (styrene- $b$-ethylbutylene- $b$-styrene) (SEBS) triblock copolymer, are composed of hard end blocks and soft middle block in the molecular architecture (Drobny, 2007; Hamley, 2003). Unlike conventional homopolymer dielectric elastomers with one rubbery phase structure, the thermoplastic dielectric elastomers exhibit a microphase-separated multi-phase structures, because strong incompatibility between middle and end blocks forces to be segregated and to form regular microphase-separated 
agglomerates due to the covalent bonding between blocks. The enthalpy of demixing is proportional to the Flory-Huggins interaction parameter $\chi$, which is inversely proportional to the temperature according to eq. (2).

$$
\chi=\frac{A}{T}+B
$$

where A and B are system dependant constants, and $\mathrm{T}$ is absolute temperature. In theory, at much higher $\chi \mathrm{N}$ than the critical value of 10.4, a block copolymer forms a strongly segregated microphase-separation, while it exhibits a miscible one phase without any phase-separation at lower $\chi \mathrm{N}$ than the critical value. The nanostructure depends not only on the fraction of each component, but also universal parameter $\chi \mathrm{N}$, where $\chi$ and $\mathrm{N}$ represent Flory-Huggins interaction parameter and degree of polymerization, respectively. They can exhibit a variety of segregation nanostructures such as sphere (S), body-centered cubic (BCC), hexagonal cylinder (C), gyroid $(\mathrm{G})$, lamellae $(\mathrm{L})$, if they have a narrow molecular weight distribution, as shown in Figure 3 (Hamley, 2003; Leibler, 1980; Matsen \& Bates, 1996).

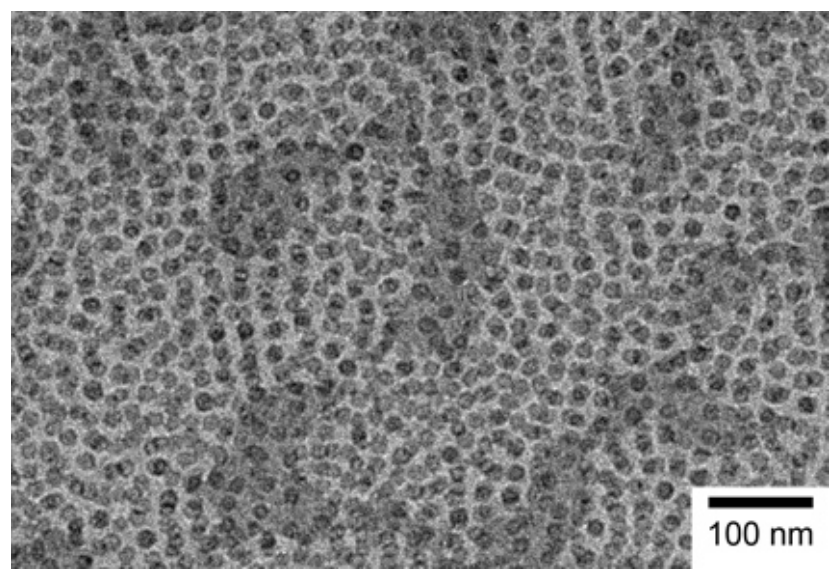

Fig. 4. TEM images of a SEBS thermoplastic dielectric elastomer gel. SEBS was $110 \mathrm{~kg} / \mathrm{mol}$ and the gel was swollen by $80 \mathrm{wt} \%$ paraffinic mineral oil.

In addition, size of the nanostructure can be simply controlled by the molecular weight. For example, inter-lamellar domain spacing $\mathrm{d}$ is expressed be eq. (3),

$$
d=a \chi^{1 / 6} N^{2 / 3}
$$

where a is a constant (Leibler, 1980; Matsen \& Bates, 1996). As a degree of polymerization increases, an inter-lamellae domain spacing increases. A number density of the nanostructure is robustly high (higher than $10^{22} \mathrm{ea} / \mathrm{m}^{3}$ for a sphere (S) nanostructure), because the nanostructure size is on the several tens nanometer scale that depends on the molecular weight of block copolymer. Figure 4 shows a representative transmission electron micrograph of SEBS thermoplastic dielectric elastomer. It has sphere nanostructures on the several tens nanometer scales. Dark sphere is composed of hard polystyrene end blocks in SEBS, and bright matrix of soft polyethybutylene middle block plasticized by mineral oil. 


\section{Shape memory property}

Shape memory property represents an ability to remember its shape or to be recovered to original shape. In the field of dielectric elastomer actuators, the shape memory property relates to the elasticity under compressive deformation. It is one of the most essential requirements of dielectric elastomers. Although applied external electric field forces a dielectric elastomer to deform in a planar extension way, the recovery to original shape should be achieved by the material's own shape memory property.

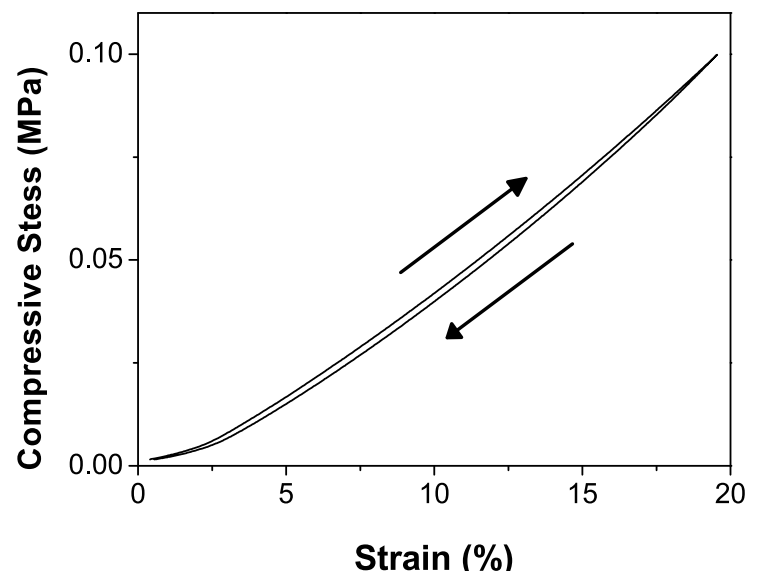

Fig. 5. Cyclic load-unload compression test of a SEBS thermoplastic dielectric elastomer (Kim et al., 2010).

Figure 5 shows shape memory property of the SEBS thermopolastic dielectric elastomer (Kim et al., 2010). With external compressive stress loaded, the thermopolastic dielectric elastomer deforms. After the stress is removed, the sample completely recovers without permanent residual strain observed. As a result, the thermoplastic dielectric elastomer have very good shape memory property.

The shape memory property of thermopolastic dielectric elastomer results from physical cross-linking, which totally differs from that of conventional homopolymer dielectric elastomer that stems from chemical cross-linking as shown in Figure 2 ( Daniel et al., 2000; Drobny, 2007; Hamley, 2003; Koo, et al., 2006). The thermoplastic dielectric elastomers form microphase-separated agglomerates in a regular fashion. Both ends of soft middle block are physically pinned by hard end-block segregation domains, because a glass transition temperature $T_{\mathrm{g}}$ of a hard block domain is much higher than room temperature, while a $T_{\mathrm{g}}$ of soft middle block is much lower than room temperature. The physical pinning does not only prohibit the soft middle block chains from experiencing chain slippage when the external stress is applied, but also makes the deformed molecular chains be recovered to original state when the external stress is removed. In addition, the physical crosslinking makes materials processible in much easy and versatile way. The materials can be easily processed and changed into various shapes and domain orientations repeatedly at temperature above $\mathrm{T}_{\mathrm{g}}$ of hard block, unlike the chemically crosslinked ones which cannot change the shape or orientation after once chemically crosslinked. 


\section{Electric actuation mechanism of thermoplastic dielectric elastomers}

\subsection{Maxwell stress}

In general, dielectric elastomers electrically actuate through the two actuation mechanisms of Maxwell stress and true electrostrictive effect, as illustrated in Figure 5. Maxwell stress is caused by the Coulomb interaction between oppositely charged electrodes. When electric field is applied onto the dielectric elastomers, the each electrode is oppositely charged. The degree of charging on the electrodes depends on the dielectric properties of the dielectrics. Maxwell stress is expressed as eq. (4), illustrated in Figure 5a (Pelrine et al, 2000).

$$
s_{M}=R_{M} E^{2}=-\frac{\varepsilon_{0} K}{2 Y} E^{2}
$$

where $R_{M}$ is the Maxwell stress contribution for $R_{33}$, and $Y$ is a compressive modulus. $K$ and $\varepsilon_{0}$ are a dielectric constant and a vacuum dielectric permittivity, respectively. As a result, when an electric field is applied across dielectric film, the dielectric film is compressed in the thickness direction, and spreads in the transverse direction. The longitudinal thickness strain $\mathrm{s}_{\mathrm{z}}$ has a quadratic relationship with the applied electric field $\mathrm{E}$.

\subsection{True electrostriction effect}

Meanwhile, the true electrostriction effect that originates from direct coupling between the polarization and mechanical response generally constitutes a contribution to the electrostrictive actuation of a dielectric elastomer as shown in Figure 5b. For a linear dielectric, the strain is induced by a change in the polarization level in the material, as expressed in eq. (5) (Su et al, 1997a, 1997b),
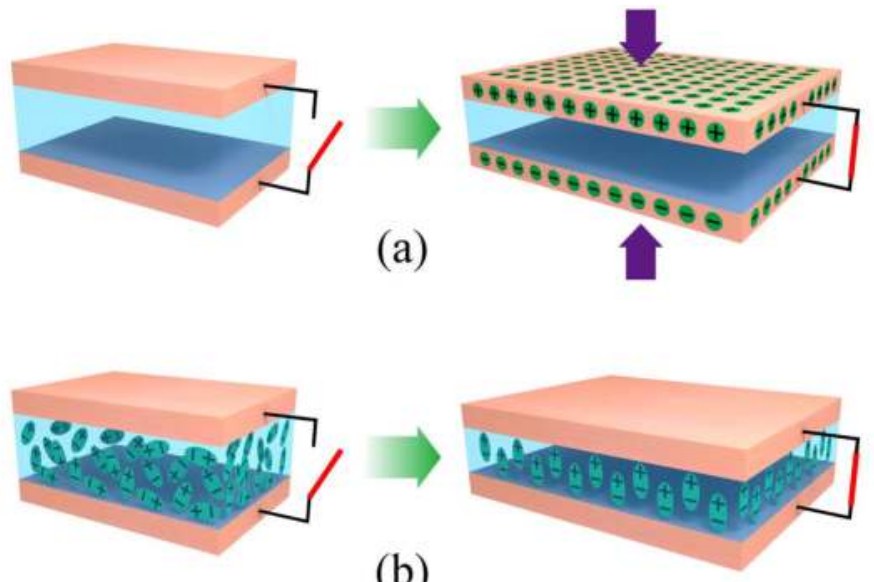

(b)

Fig. 6. Schematic illustrations of two electric actuation mechanisms of a dielectric elastomer. (a) Maxwell stress that originates from the Coulomb interaction between oppositely charged compliant electrodes. It is known as a dominant contributor for the electric actuation of a dielectric elastomer. (b) A true electrostrictive effect that originates from direct coupling between the polarization and electromechanical strain response. 


$$
s_{E S}=R_{E S} E^{2}=Q P^{2}=Q \varepsilon_{0}{ }^{2}(K-1)^{2} E^{2}
$$

where $R_{\mathrm{ES}}$ is a true electrostriction contribution for $R_{33}$, and $P$ and $Q$ are a polarization and a electrostrictive coefficient of the material, respectively. Here $Q$ is a material related parameter that determines a true electrostrictive strain to a given polarization.

To date, it was a well-known common sense that electric actuation of a dielectric elastomer is usually dominated by Maxwell stress. Thus, many endeavors have mainly focused on enhancing a dielectric constant of dielectric elastomer itself or dispersing high dielectric fillers in order to improve the Maxwell stress effect and thus to enhance the electric actuation (Huang \& Zhang, 2004, 2005; Xu et al, 2002; Zhang et al., 2002). Unfortunately, the true electrostriction effect, in particular, $Q$ parameter is rarely taken into careful consideration in the electric actuation of dielectric elastomers.

\subsection{Electric actuation of thermoplastic dielectric elastomers}

The unique actuation performance of several SEBS thermoplastic dielectric elastomers with same styrene content and different molecular weights was reported by Shankar et al. (2007). Sample films were prepared from their mineral oil swollen gel and their prestrained films were fixed on the circular rigid frame for the actuation test as illustrated in Figure 7. Both side of film surfaces were coated with compliant electrodes such as carbon grease. Actuation strain was evaluated via monitoring the area change of active area in which electric field is applied cross the film thickness direction.

A areal strain represents an active area change relative to an initial active area. The electric areal strains were evaluated from a sequence of digital images acquired from the active area of the SEBS gel film upon exposure to electric field varying in strength. Active area of the sample film increased as the electric field increased. That is, the areal strains increased with the applied electric field. The maximum areal actuation strain increased with decreasing SEBS concentration in the gel and increasing SEBS molecular weight. Break-down electric field decreased sharply with decreasing SEBS concentration, while it increased with increasing size and number density of $S$ (styrene) domain.

In Table 2 and Figure 8, actuation behaviors of SEBS gels were compared with those of other dielectric polymers (Shankar et al., 2007a, 2007b, 2007c, 2008; Vargantwar, 2011). Although the SEBS gel materials possess low-to-moderate energy densities, they exhibit exceptional electroactive behavior owing to a easy composition tunability. The lowest modulus SEBS gel exhibited a 14-55\% increase in maximum areal actuation strain relative to the VHB4910 acrylic at markedly lower breakdown electric fields $(22-32 \mathrm{~V} / \mu \mathrm{m}$ vs $161 \mathrm{~V} / \mu \mathrm{m})$ and $94-103 \%$ increase relative to the HS3 silicone elastomer. In particular, the SEBS gels can exhibit substantially higher displacements than other dielectrics at very reduced electric fields. This is a very invaluable feature, because conventional dielectric elastomers generally require much higher actuation voltage in comparison with other electroactive materials such as ionic polymer-metal composites, and conducting polymers. That is, one of the greatest advantages of the SEBS thermoplastics is that not only physical properties of the thermoplastic elastomer gels such as compressive modulus and strength, but also electromechanical actuation properties can be easily tuned via simple changing a oil content 
in a gel. However, the underlying actuation mechanism of thermoplastic dielectric elastomers were still behind a veil.

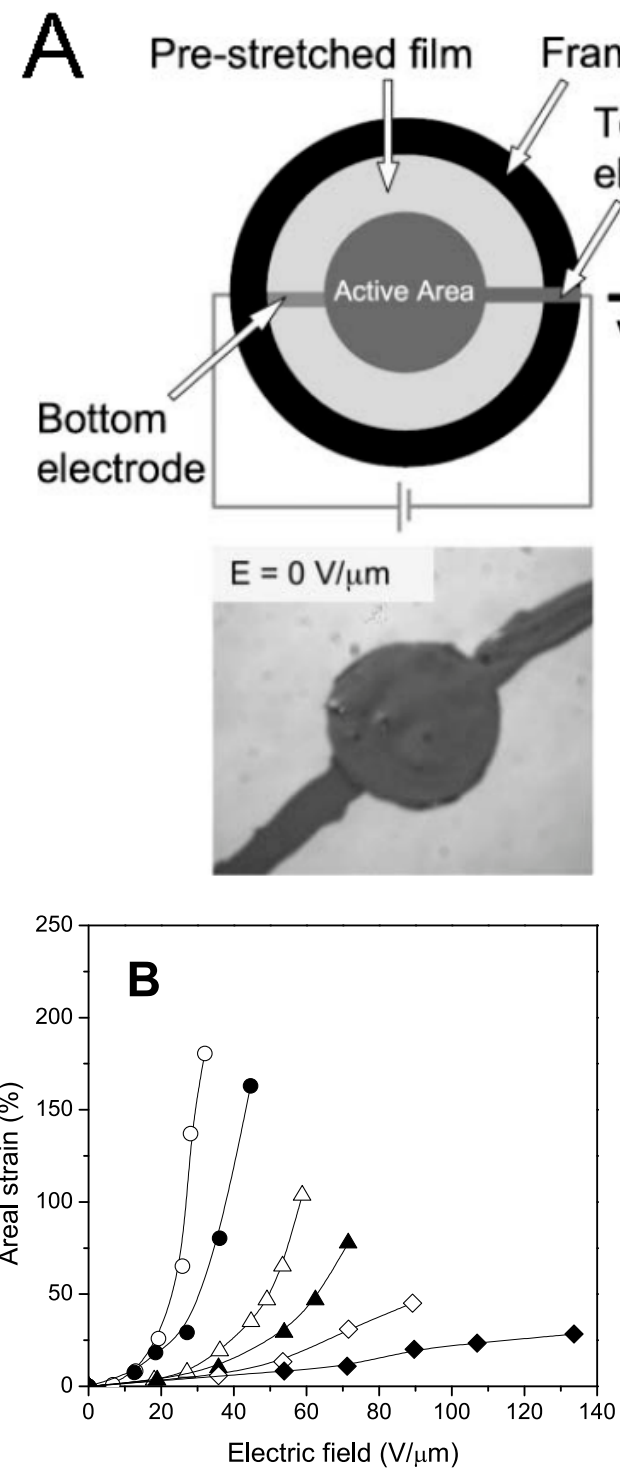

\section{Top} electrode

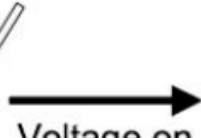

Voltage on
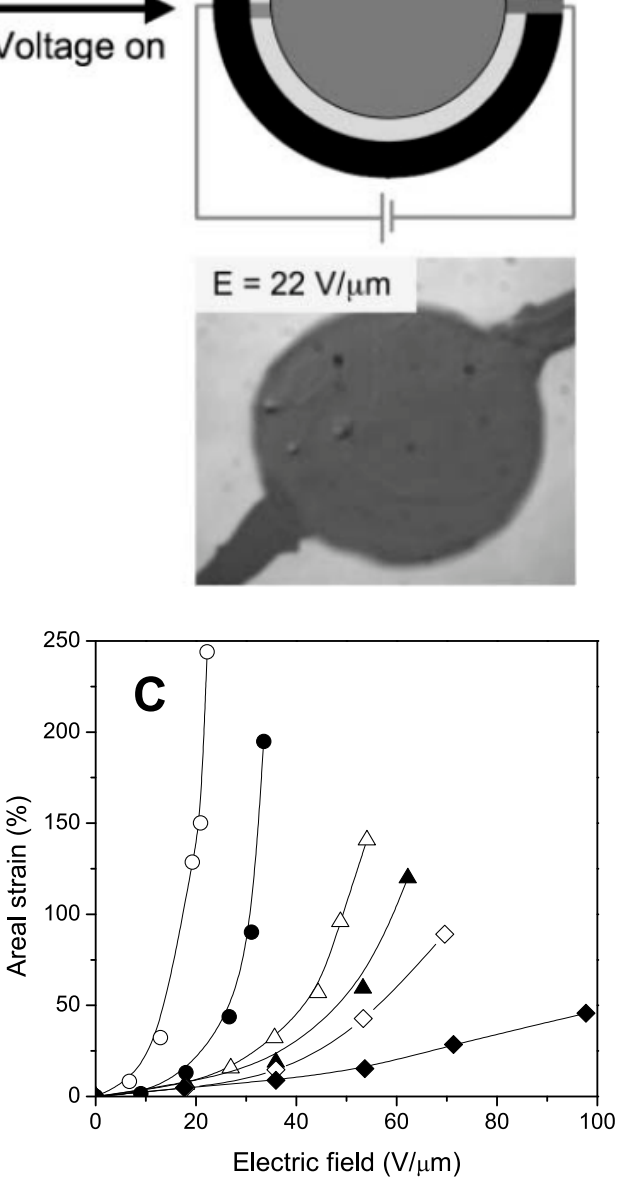

Fig. 7. (a) Circular experimental setup for the strain test of the SEBS gel films and the optical images of the films in the presence of applied electric field. (b) and (c) actuation strains of the SEBS161 $(\mathrm{Mw}=161 \mathrm{~kg} / \mathrm{mol})$ and SEBS217 $(\mathrm{Mw}=217 \mathrm{~kg} / \mathrm{mol})$ triblock copolymer gels at various solid concentrations (in wt \%) : $5(\mathrm{O}), 10(\bullet), 15(\triangle), 20(\boldsymbol{\Delta}), 25(\diamond), 30(\bullet)$.(Shankar et al., 2007a) 


\begin{tabular}{cccccccc}
\hline Type & $\begin{array}{c}\text { Polymer } \\
\text { fraction } \\
(\%)\end{array}$ & $\begin{array}{c}\text { Prestrain } \\
(\mathrm{x} \%, \mathrm{y} \%)\end{array}$ & $\begin{array}{c}\text { Tensile } \\
\text { modulus } \\
(\mathrm{kPa})\end{array}$ & $\begin{array}{c}\text { Maximum } \\
\text { areal strain } \\
(\%)\end{array}$ & $\begin{array}{c}\text { Breakdown } \\
\text { electric field } \\
\left(\mathrm{v} \mathrm{m}^{-1}\right)\end{array}$ & $\begin{array}{c}\text { Energy } \\
\text { density } \\
\left(\mathrm{k} \mathrm{Jm}^{-3}\right)\end{array}$ & Ref. \\
\hline $\begin{array}{c}\text { Acrylic } \\
\text { VHB4910 }\end{array}$ & 100 & 300,300 & $1000-3000$ & 158 & 161 & 3400 & {$[\mathrm{a}],[\mathrm{b}]$} \\
$\begin{array}{c}\text { Silicone } \\
\text { HS3 }\end{array}$ & 100 & 68,68 & 130 & 93 & 57 & 98 & {$[\mathrm{a}]$} \\
ENP & & & & & & & \\
SEBS161 & $5-30$ & 300,300 & $7-163$ & $180-30$ & $32-133$ & $141-151$ & {$[\mathrm{c}][\mathrm{d}]$} \\
SEBS217 & $5-30$ & 300,300 & $2-133$ & $245-47$ & $22-98$ & $119-139$ & {$[\mathrm{c}][\mathrm{d}]$} \\
\hline
\end{tabular}

[a] Referred from Pelrine et al., 2000a.

[b] Referred from Madden et al., 2004.

[c] Referred from Kornbluh et al., 1999.

[d] Referred from Shankar et al., 2007.

Table 2. Actuation behavior of SEBS gels varying in composition and other dielectric elastomers (Shankar et al., 2007a, 2007c).

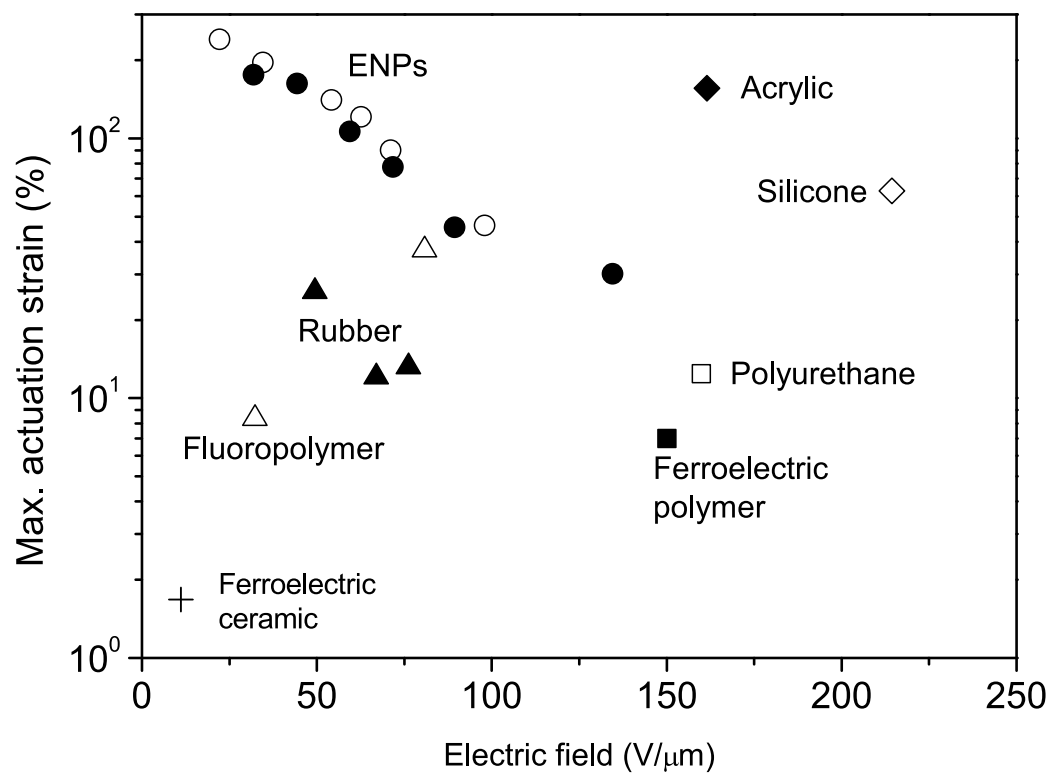

Fig. 8. Maximum actuation strain of several classes of dielectric elastomers as a function of electric field. ENPs indicate the thermoplastic dielectric elastomers such as SEBS (Shankar et al., 2007a).

Kim et al (2011) provided an important clue for the better understanding of the underlying actuation mechanism of thermoplastic dielectric elastomers. They verified via non-contact strain measurement that thermoplastic dielectric elastomers considerably actuate without Maxwell stress contribution. Non-contact represents that a sample film does not have any direct contact with the electrodes as illustrated in Figure 9a. The thermoplastic dielectric 
elastomer film was sandwiched with the transparent glass on which FTO electrodes were patterned. Insulate polyimide film spacers were inserted between the sample film and the electrodes in order to avoid the contact between the sample film and the electrodes. Maxwell stress results from the accumulated electron charges on the sample surface, which is injected from the electrodes. The non-contact setup prevents charge injection through the electrodes. As a result, non-contact experiment excludes Maxwell stress contribution in the electric actuation of the nanostructured thermoplastic elastomer actuators. A poly (styrene$b$-ethylbutylene- $b$-styrene) (SEBS) and a poly (styrene- $b$-ethylbutylene- $b$-styrene)-graftmaleic anhydride (MA) triblock copolymer gels were used as thermoplastic dielectric elastomers. Figure $9 \mathrm{~b}$ showed the electromechanical strain responses of the SEBS20 and MA20 with conventional method (contact experiment) and with non-contact experiment at the constant applied electric field strength of $5 \mathrm{~V} / \mu \mathrm{m}$. The SEBS20 and MA20 films without a direct contact with electrodes still experienced the electric actuation under the electric field. The electric actuation strains of the SEBS20 and MA20 gels measured with non-contact mode was comparable with those with contact mode.

Kim et al.(2010, 2011) carefully analyzed the degree of contribution of each actuation mechanism mode to total actuation via a in-situ synchrotron small angle X-ray scattering (SAXS) measurement. They introduced a synchrotron SAXS method for the accurate actuation strain measurement of thermoplastic dielectric elastomers. Accurate strain measurement is no doubt essential for better understanding of its underlying actuation mechanism of the dielectric elastomer. Usually, the thickness strain of the dielectric elastomer film has been evaluated by measuring lateral areal actuation strain under the assumption of an isochoric condition. The areal strain used to be measured by captured realtime video imagery. In some research studies, the thickness strain was directly observed by using a laser displacement sensor which can detect the distance between the sample and the sensor. Both methods are very useful because they provide a non-destructive method of measurement. However, unfortunately, an out-of-plane flexure motion or a bending motion is inevitably observed in the electromechanical actuation of most unstrained dielectric elastomers due to non-uniformity in sample thickness or electrode thickness as well as large expansion in the lateral strain. Fortunately, the well defined nanostructures of the thermoplastic dielectric elastomers make it possible not only to measure the true electromechanical strain from the nanostructure dimension change monitored, but also to monitor the directional dependence of the dimension change in nanoscale order, via an insitu synchrotron SAXS. On the basis of actuation strains measured via synchrotron SAXS measurement, a comparison between the measured $R_{33}$ and the contribution from the Maxwell stress effect, $R_{\mathrm{M}}$ of SEBS and MA thermoplastic elastomers at $15 \mathrm{~V} / \mu \mathrm{m}$, was presented in Figure 10. The sensitivity of the strain, $R_{33}$, and the contribution from the Maxwell stress effect, $R_{\mathrm{M}}$, could be calculated by eq. (1) and eq. (5), respectively, as the field induced strain is proportional to the square of the applied electric field. The contribution from the electrostrictive effect, $R_{\mathrm{ES}}$, can be simply obtained by $R_{33}-R_{\mathrm{M}}$. They concluded that the true electrostriction contribution, $R_{\mathrm{ES}}$, dominates the electric actuation of the thermoplastic dielectric elastomer.

Table 3 lists electrostrictive coefficients, $Q$, of the SEBS and MA thermoplastic dielectric elastomers and other dielectric materials, obtained using eq. (5). Both the SEBS and MA had 
ultra-high $Q$ values, compared with those of conventional ferroelectric materials such as inorganic PZT and organic PVDF, and even compared with a polyurethane dielectric elastomer, a fluoroelastomer, and a polyurethane-based molecular composite with highly improved dielectric permittivity (Kim et al. 2011).

Table 3. Comparison of thermoplastic dielectric elastomers with materials commonly employed in electric actuation (Kim et al., 2011).

\begin{tabular}{ccccc}
\hline Materials & $Q\left(\mathbf{m}^{4} / \mathrm{C}^{2}\right)$ & $K$ & $\boldsymbol{Y}(\mathbf{M P a})$ & $\boldsymbol{R}_{33}\left(\mathbf{m}^{2} / \mathbf{N}^{2}\right)$ \\
\hline PZT[a] & 0.096 & 2,000 & $6.3 \times 10^{4}$ & $-[\mathrm{f}]$ \\
PVDF[b] & -2.0 & 9 & $3.3 \times 10^{3}$ & $-[\mathrm{f}]$ \\
Polyurethane[a] & $-150 \sim-450$ & $4 \sim 8$ & $20 \sim 200$ & $-2.0 \times 10^{-18}$ \\
Polyurethane/CuPc/PANI [c] & $-5 \sim-300$ & $100 \sim 800$ & $80-140$ & $-2.5 \times 10^{-16}$ \\
Fluoroelastomer [d] & $-5.2 \times 10^{3}$ & 12.1 & 2.5 & $-7.8 \times 10^{-17}$ \\
SEBS [e] & $-7.4 \times 10^{5 \sim-}$ & $2.32 \sim 2.36$ & $0.37 \sim 1.23$ & $-1.3 \times 10^{-16 \sim-}$ \\
& $8.4 \times 10^{4}$ & & & $3.1 \times 10^{-17}$ \\
MA [e] & $-1.1 \times 10^{6 \sim-}$ & $2.55 \sim 2.62$ & $0.36 \sim 1.42$ & $-2.4 \times 10^{-16 \sim-}$ \\
& $1.3 \times 10^{5}$ & & & $3.4 \times 10^{-17}$ \\
\hline
\end{tabular}

Table 3. Comparison of the SEBS and MA thermoplastic dielectric elastomers with materials commonly employed in electromechanical actuation. [a] Referred from Zhang et al., 1997, [b] Referred from Furukawa \& Seo, 1990, [c] Referred from Huang \& Zhang, 2005, [d]

Referred from Pelrine et al, 2000, [e] Referred from Kim et al., 2011, [f] PZT and PVDF follow piezoelectricity that a strain response is linearly proportional to electric field.

It is very interesting that the true electrostriction effect dominates the actuation of the thermoplastic dielectric elastomer. This unique actuation behavior is considerably different from that of a conventional dielectric elastomer, where the Maxwell stress contribution is dominant in a conventional dielectric elastomer ( $\mathrm{Su}$ et al, 1997a, 1997b). This strong true electrostriction effect might be attributed to the dielectric mismatched periodic nanostructures. The interfaces between nanodomains result in the development of an inhomogeneous electric field across the film thickness (Guiffard et al., 2006; Kim et al., 2011; Li \& Rao, 2002; Shankar et al., 1997; Su et al, 1997a, 1997b; Zhang, et al, 1997). The nonuniform field distribution can enhance the strain response because coupling between the strain and electric field in a dielectric elastomer is described by a quadratic relationship, delineated by eq. (4) and eq. (5) (Pelrine et al., 2000). The thermoplastic dielectric elastomers are typical multiphase systems with mismatched dielectric constants, and the sphere domain of polystyrene has a relatively higher permittivity than the matrix domain. The thermoplastic dielectric elastomer includes a ultrahigh density of dielectric mismatched nanodomains, higher than $10^{22} \mathrm{ea} / \mathrm{m}^{3}$. In case of the dispersion phase has a higher dielectric constant than the matrix phase, the induced dipole moment is parallel to the electric field. The resulting polarized micelles tend to attract each other due to electrostatic interactions, similar to particles in an dielectric medium and an electrorheological fluid (Boker et al., 2002; Boissy et al, 1995; Giacomelli et al, 2008; Morkved, et al., 1996). The additional attraction among adjacent polarized spheres might build a unique characteristic of thermoplastic dielectric elastomer actuation. 
(a)

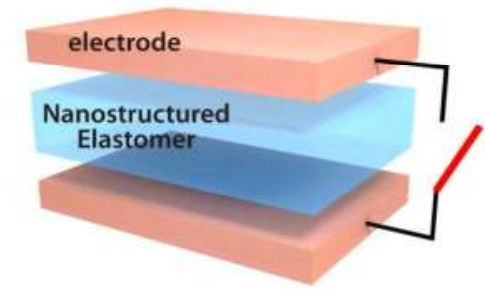

Voltage-Off

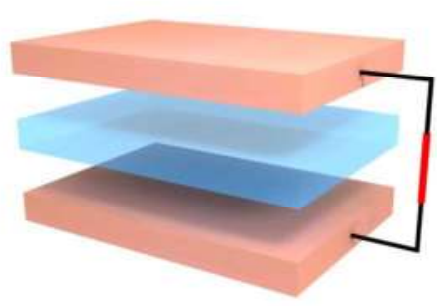

Voltage-On

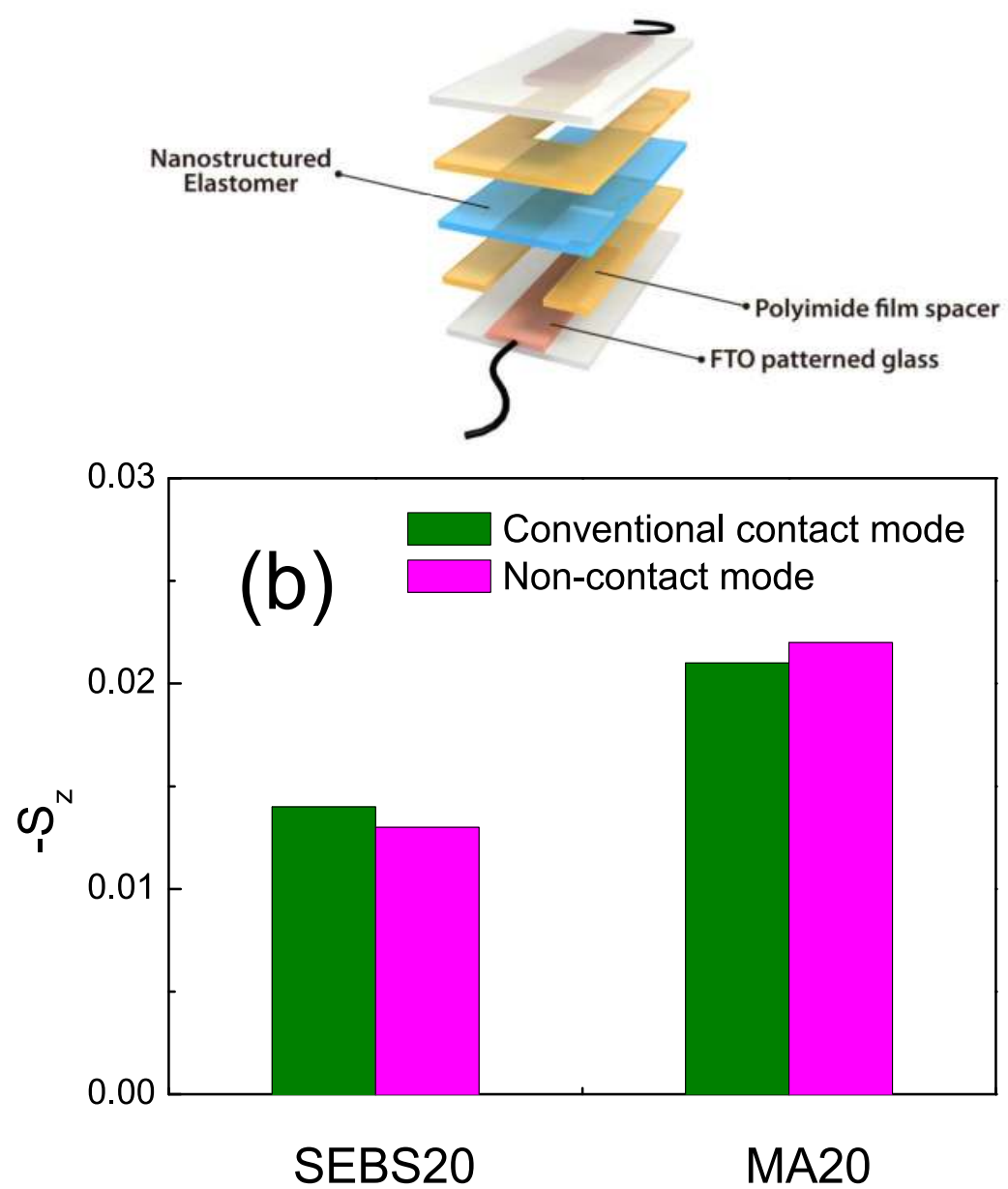

Fig. 9. (a) The illustration of a non-contact strain measurement setup and (b) The electromechanical strain responses of the SEBS20 and MA20 gels at the constant applied electric field strength of $5 \mathrm{~V} / \mu \mathrm{m}$. (Kim et al., 2011) 


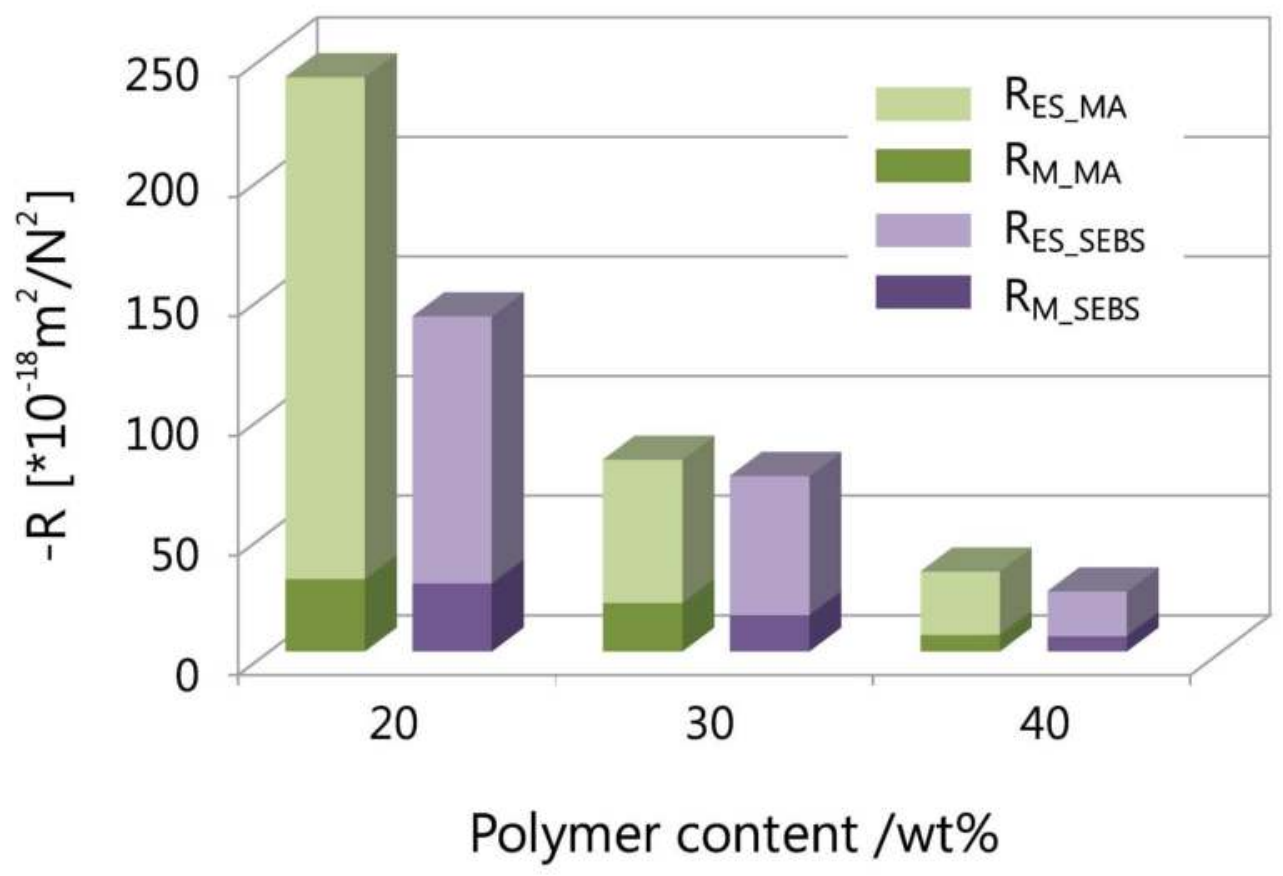

Fig. 10. Comparison between Maxwell stress contribution, $R_{M}$ and true electrostriction contribution, $\mathrm{R}_{\mathrm{ES}}$, of SEBS and MA thermoplastic dielectric elastomer to the strain sensitivity, $R_{33}$ at $15 \mathrm{~V} / \mu \mathrm{m}$. $R_{33}$ represents the sum of $R_{M}$ and $R_{E S}$ (Kim et al., 2011).

\section{Conclusion}

In this book, we demonstrated that thermoplastic dielectric elastomers are distinguished from conventional homopolymer dielectric elastomers such as acrylics and silicones in many aspects such as nanostructure morphology, shape memory property and electric actuation mechanism. Unlike conventional homopolymer dielectric elastomers with one phase structure, these thermoplastic dielectric elastomers exhibit a well defined microphaseseparated nanostructure owing to the molecular architecture. That kind of nanostructure results in the physical-crosslink-induced shape memory effect which is quite different from chemical-crosslink-induced shape memory effect of conventional dielectric elastomers. Most of all, thermoplastic dielectric elastomers have much larger true electrostrictive coefficients than conventional homopolymer dielectric elastomers, thus show the much fabulous electric actuation properties even at low electric field. Such unique behavior basically stems from the presence of a high density of dielectric mismatched nanostructures. As a result, we consider thermoplastic dielectric elastomers as fascinating actuation materials, although many challenges still remains for the real applications. We hope that, in future, this thermoplastic dielectric elastomer approach contributes to opening an era of polymer transducers. 


\section{Acknowledgment}

This work was financially supported by a grant from the Fundamental R\&D Program for Core Technology of Materials funded by the Ministry of Knowledge Economy, Republic of Korea, and partially by a grant from the Nano Hybrids Center of Korea Institute of Science and Technology (KIST).

\section{References}

Bar-Cohen, Y. (2004). Electroactive Polymer (EAP) Actuators as Artificial Muscles: Reality, Potential, and Challenges, SPIE press, Bellingham, ISSN 9780819452979

Bay, L., West, K., Sommer-Larsen, P., Skaarup, S. \& Benslimane, M. Z. (2003). A Conductng Polymer Artificial Muscle with 12\% Linear Strain, Adv. Mater., Vol. 15, pp. 310- 313. ISSN 0935-9648

Boissy, C., Atten, P. \& Foulc, J. N. (1995). On a Negative Electrorheological Effect, J. Electrostatics, Vol. 35, pp. 13-20, ISSN 0304-3886

Boker, A., Elbs, H., Hansel, H., Knoll, A., Ludwigs, S., Zettl, H., Urban, V., Abetz, V., Muller, A. H. E. \& Krauch, G. (2002). Microscopic Mechanisms of Eletric-Field-Induced Alignment of Block Copolymer Microdomains, Phys. Rev. Lett., Vol. 89, pp. 135502, ISSN 0031-9007

Brochu, P. \& Pei, Q. (2010). Advances in Dielectric Elastomers for Actuators and Artificial Muscles, Macromol. Rapid Commun., Vol. 31, pp. 10-36, ISSN 1022-1336

Carpi, F., De Rossi, D., Kornbluh, R., Pelrine, R. \& Sommer-Larsen, P. (2008) Dielectric Elastomers as Electromechanical Transducers, Elsevier Ltd., Oxford, UK, ISSN 978-008-047488-5

Carpi, F. \& Smela, E. (2009). Biomedical Applications of Electroactive Polymer Actuators, John Wiley \& Sons, Chichester, West Sussex, UK, ISSN 9780470773055

Chmidt, K., Schoberth, H. G., Ruppel, M., Zettl, H., Hansel, H., Weiss, T. M., Urban, V., Krausch, G. \& Boker, A. (2008). Reversible Tuning of a Block-Copolymer Nanostructure Via Electric Fields, Nature Materials, Vol. 7, pp. 142-145, ISSN 14761122

Daniel, C., Hamley, I. W. \& Mortensen, K. (2000). Effect of Planar Extension of the Strurcture and Mechanical Properties of Polystyrene-poly(ethylene-co-butylene)- polystyrene Triblock Copolymers, Polymer, Vol. 41, pp. 9239-9247, ISSN 0032- 3861

Drobny, J. G. (2007). Handbook of Thermoplastic Elastomers, William Andrew, New York, NY, USA, ISSSN 978-0-8155-1549-4

Giacomelli, F. C., Riegel, I. C., Petzhold, C. L. \& da Silveria, N. P. (2008). Block copolymer solutions under external electric field: Dynamic Behavior Monitored by Light Scattering, Macromolecules, Vol. 41, pp. 2677-2682, ISSN 0024-9297

Guiffard, B., Seveyrat, L., Sebald, G. \& Guyomar, D. (2006). Enhanced Electric Field-Induced Strain in Non-Percolative Carbon Nanopowder/Polyurethane Composites, J. Phys. D: Appl. Phys., Vol. 39, pp. 3053-3057, ISSN 0021-8979

Furukawa, T. \& Seo, N. (1990). Electrostriction as the Origin of Piezoelectricity in Ferroeletric Polymers, Jpn. J. Appl. Phys., Vol. 29, pp. 675-680, ISSN 0021-4922

Huang, C. \& Zhang, Q. M. (2004). Enhanced Dielectric and Electromechanical Responses in High Dielectric Constant All-Polymer Percolative Composites, Adv. Funct. Mater., 
Vol. 14, pp. 501-506, ISSN 1616-301X

Huang, C. \& Zhang, Q. M. (2005). Fully Functionalized High-Dielectric-Constant Nanophase Polymers with High Electromechanical Response, Adv. Mater., Vol. 17, pp. 11531158, ISSN. 0935-9648

Jang, Y., Kato, T., Ueki, T. \& Hirai, T. (2011). Performance of PMMA-PnBA-PMMA Dielectric Film Actuator with Controllable Phase Morphology, Sensors and Actuators A: Physical, Vol. 168, pp. 300-306, ISSN 0924-4247

Kim, B., Park, Y. D., Kim, J., Hong, S. M. \& Koo, C. M. (2010). Measuring True Electromechanical Strain of Electroactive Thermoplastic Elastomer Gels Using Synchrotron SAXS, J. Polym. Sci. Part. B : Polym. Phys., Vol. 48, pp. 2392-2398, ISSN 0887-6266

Kim, B., Park, Y. D., Min, K. H., Lee, J. H., Hwang, S. S., Hong, S. M., Kim, B. H., Kim, S. O. \& Koo, C. M. (2011). Electric Actuation of Nanostructured Thermoplastic Elastomer Gels with Ultralarge Electrostriction Coefficients, Adv. Mater., Vol. 21, pp. 32423249, ISSN. 0935-9648

Kim, K. J. \& Tadokoro, S. (2007). Electroactive Polymers for Robotic Applications: Artificial Muscles and Sensors, Springer, London, UK, ISSN 184628371X

Koo, C. M., Hillmyer, M. A. \& Bates, F. S. (2006). Structure and Properties of SemicrystallineRubbery Multiblock Copolymers, Macromolecules, Vol. 39, pp. 667-677, ISSN 00249297

Kornbluh, R. Pelrine, R., Joseph, J., Heydt, R., Pei, Q. \& Chiba, S. (1999). High-Field Electrostriction of Elastomeric Polymer Dielectrics for Actuation, Proc. SPIE-int. Soc. Opt. Eng., Vol. 3669, pp. 149-161, ISSN

Kornbluh, R., Pelrine, R., Pei, Q., Heydt, R., Standord, S., Oh, S. \& Eckerle, J. (2002). Electrroelastomers: Applications of Dielectric Elastomer Transducers for Actuation, Generation, and Smart Structures, Proc. SPIE, Vol. 4698, pp. 254-270, ISSN

Kornbluh, R., Pelrine, R., Pei, Q., Oh, S. \& Joseph, J. (2000). Ultrahigh Strain Response of Field-Actuated Elastomeric Polymers, Proc. SPIE, Vol. 3987, pp. 51-64, ISSN

Lagoudas, D. C. (2008). Shape Memory Alloys: Modeling and Engineering Applications, Springer, ISSN 0387476849

Leibler, L. (1980).Theory of Microphase Separation in Block Copolymer, Macromolecules, Vol. 13, pp. 1602-1617 ISSN 0024-9297

Li, J. Y. \& Rao, N. (2002). Dramatically Enhanced Effective Electrostriction in Ferroelectric Polymeric Composites, Appl. Phys. Lett., Vol. 81, pp. 1860-1862, ISSN 0003-6951

Madden, J. D. W., Vandesteeg, N. A., Anquetil, P. A., Madden, P. G. A., Takshi, A., Pytel, R. Z. , Lafontaine, S. R., Wieringa, P. A. \& Hunter, I. W (2004). Artificial Muscle Technology: Physical Principles and Naval Prospects, IEEE L. Oceanic Eng., Vol. 29, pp. 706-728, ISSN 0364-9059

Matsen, M. W. \& Bates, F. S. (1996). Unifying Weak- and Strong-Segregation Block Copolymer Theories, Macromolecules, Vol. 29, pp. 1091-1098, ISSN 0024-9297

Hamley, I. W. (2003). The Physics of Block Copolymers, Oxford University Press, Oxford, UK, ISSN 0198502184

Morkved, T. L., Lu, M., Urbas, A. M., Ehrichs, E. E., Jaeger, H. M., Mansky, P. \& Russell, T. P. (1996). Local Control of Microdomain Orientation in Diblock Copolymer Thin Films with Electric Fields, Science, Vol. 273, pp. 931-933, ISSN 0036-8675 
Nemat-Nasser, S. \& Wu, Y. X. (2003). Comparative Experimental Study of Ionic PolymerMetal Composites with Different Backbone Ionomers and in Various Cation Forms, J. Appl. Phys., Vol. 93, pp. 5255-5267, ISSN 0021-8979

O'Halloran, A., O'Malley, F. \& McHugh, P. (2008). A Review on Dielectric Elastomer Actuators, Technology, Applications, and Challenges, J. Appl. Phys., Vol. 104, pp. 071101, ISSN 0021-8979

Pelrine, R., Kornbluh, R., Joseph, J., Heydt, R., Pei, Q. \& Chiba, S. (2000). High-Field Deformation of Elastomeric Dielectrics for Actuators, Mater. Sci. Eng. C, Vol. 11, pp. 89-100, ISSN 0928-4931

Pelrine, R., Kornbluh, R., Pei, Q. \& Joseph, J. (2000). High-Speed Electrically Actuated Elastomers with Strain Greater than $100 \%$, Science, Vol. 287, pp. 836-839, ISSN 00368675

Pons, J. L. (2005). Emerging Actuator Technologies: A Micromechatronic Approach, Wiley, NJ, ISSN 978-0-470-09197-5

Shahinpoor, M, Kim, K. J. \& Mojarrad, M. (2007). Artificial Muscles: Applications of Advanced Polymeric Nanocomposites, CRC press Taylor \& Francis Group, FL, ISSN 1584887133

Shankar, R., Ghosh, T. K. \& Spontak, R. J. (2007). Electroactive Nanostructured Polymers as Tunable Actuators, Adv. Mater., Vol. 19, pp. 2218-2223, ISSN 0935-9648

Shankar, R., Ghosh, T. K. \& Spontak, R. J. (2007). Electromechanical Response of Nanostructured Polymer Systems with no Mechanical Pre-strain, Macromol. Rapid Commun., Vol. 28, pp. 1142-1147, ISSN 1022-1336

Shankar, R., Ghosh, T. K. \& Spontak, R. J. (2007). Dielectric Elastomers as Next-generation Polymeric Actuators, Soft Matter, Vol. 3, pp. 1116-1129, ISSN 1744-6848

Shankar, R., Krishnan, A. K., Ghosh, T. K. \& Spontak, R. J. (2008). Triblock Copolymer Organogels as High Performance Dielectric Elastomers, Macromolecules, Vol. 41, pp. 6100-6109, ISSN 0024-9297

Su, J., Ting, R. Y. \& Zhang, Q. M. (1997). Space-Charge-Enhanced Electromechanical Responses of Polyurethane Elastomers, Appl. Phys. Lett., Vol. 71, pp. 386-388, ISSN 0003-6951

Su, J., Zhang, Q. M., Kim, C. H., Ting, R. Y. \& Capps, R. (1997). Effects of Transitional Phenomena on the Electric Field Induced Strain-Electrostrictive Response of a Segmented Polyurethane Elastomer, J. Appl. Poly. Sci., Vol. 65, pp. 1363-1370, ISSN 0021-8995

Vargantwar, P. H., Shankar, R., Krishnan, A. S., Ghosh, T. K. \& Spontak, R. J. (2011). Exceptional Versatility of Solvated Block Copolymer/Ionomer Networks as Electroactive Polymers, Soft Matter, Vol. 7, pp. 1651-1655, ISSN 1744-6848

Xu, H., Li, H., Zhang, Q. M., Kavarnos, G. J., Ting, R. Y., Abdel-Sadek, G. \& Belfield, K. D. (2002). High Electromechanical a Poly(vinylidene fluoride-trifluoroethylenechlorofluoroethylene) Terpolymer, Adv. Mater., Vol. 14, pp. 1574-1577, ISSN 09359648

Zhang, Q. M., Li, H., Poh, M., Xia, F., Cheng, Z. Y., Xu, H. \& Huang, C. (2002). An AllOrganic Composite Actuator Material with a High Dielectric Constant, Nature, Vol. 419, pp. 284-287, ISSN 0028-0836 
Zhang, Q. M., Su, J., Kim, C. H., Ting, R. Y. \& Capps, R. (1997). An Experimental Investigation of Electromechanical Responses in a Polyurethane Elastomer, J. Appl. Phys., Vol. 81, pp. 2770-2776, ISSN 0021-8979 


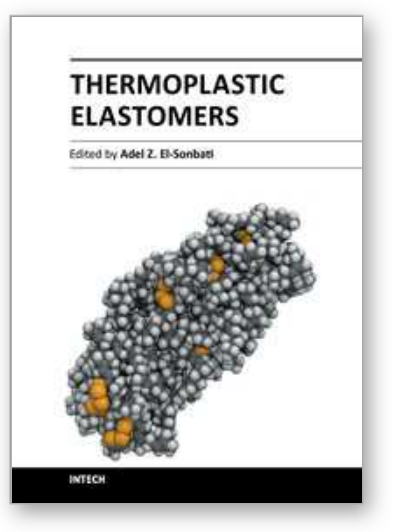

\author{
Thermoplastic Elastomers \\ Edited by Prof. Adel El-Sonbati
}

ISBN 978-953-51-0346-2

Hard cover, 416 pages

Publisher InTech

Published online 28, March, 2012

Published in print edition March, 2012

Thermoplastics can be used for various applications, which range from household articles to the aeronautic sector. This book, "Thermoplastic Elastomers", is comprised of nineteen chapters, written by specialized scientists dealing with physical and/or chemical modifications of thermoplastics and thermoplastic starch. Such studies will provide a great benefit to specialists in food, electric, telecommunication devices, and plastic industries. Each chapter provides a comprehensive introduction to a specific topic, with a survey of developments to date.

\title{
How to reference
}

In order to correctly reference this scholarly work, feel free to copy and paste the following:

Chong Min Koo (2012). Electroactive Thermoplastic Dielectric Elastomers as a New Generation Polymer Actuators, Thermoplastic Elastomers, Prof. Adel El-Sonbati (Ed.), ISBN: 978-953-51-0346-2, InTech, Available from: http://www.intechopen.com/books/thermoplastic-elastomers/electroactive-thermoplastic-dielectricelastomers-as-a-new-generation-polymer-actuators-

\section{INTECH}

open science | open minds

\section{InTech Europe}

University Campus STeP Ri

Slavka Krautzeka 83/A

51000 Rijeka, Croatia

Phone: +385 (51) 770447

Fax: +385 (51) 686166

www.intechopen.com

\section{InTech China}

Unit 405, Office Block, Hotel Equatorial Shanghai

No.65, Yan An Road (West), Shanghai, 200040, China

中国上海市延安西路 65 号上海国际贵都大饭店办公楼 405 单元

Phone: +86-21-62489820

Fax: +86-21-62489821 
(C) 2012 The Author(s). Licensee IntechOpen. This is an open access article distributed under the terms of the Creative Commons Attribution 3.0 License, which permits unrestricted use, distribution, and reproduction in any medium, provided the original work is properly cited. 